\title{
Bright Light-Emitting Diodes based on Organometal Halide Perovskite
}

\author{
Zhi-Kuang Tan ${ }^{1}$, Reza Saberi Moghaddam ${ }^{1}$, May Ling Lai ${ }^{1}$, Pablo Docampo ${ }^{2}$, Ruben Higler ${ }^{1}$, Felix \\ Deschler ${ }^{1}$, Michael Price ${ }^{1}$, Aditya Sadhanala ${ }^{1}$, Luis M. Pazos ${ }^{1}$, Dan Credgington ${ }^{1}$, Fabian Hanusch ${ }^{2}$, \\ Thomas Bein ${ }^{2}$, Henry J. Snaith ${ }^{3}$ and Richard H. Friend ${ }^{1 *}$ \\ ${ }^{1}$ Cavendish Laboratory, University of Cambridge, JJ Thomson Avenue, Cambridge CB3 OHE, UK. \\ ${ }^{2}$ Ludwig-Maximilians-Universität München, Butenandtstraße 11, 81377, München, Germany. \\ ${ }^{3}$ Department of Physics, University of Oxford, Clarendon Laboratory, Parks Road, Oxford OX1 3PU, \\ UK. \\ [*] rhf10@cam.ac.uk
}

Solid state light-emitting devices based on direct bandgap semiconductors have, over the past two decades, been utilized as energy efficient sources of lighting. However, the fabrication of these devices typically relies on expensive high temperature and high vacuum processes, rendering them uneconomical for use in large area displays. Here, we report high brightness lightemitting diodes based on solution-processed organometal halide perovskites. We demonstrate electroluminescence in the near-infrared, green and red by tuning the halide compositions in the perovskite. In our infrared device, a thin $15 \mathrm{~nm}$ layer of $\mathrm{CH}_{3} \mathrm{NH}_{3} \mathrm{Pbl}_{3-\mathrm{x}} \mathrm{Cl}_{x}$ perovskite emitter is sandwiched between larger bandgap titanium dioxide $\left(\mathrm{TiO}_{2}\right)$ and poly $(9,9$ '-dioctylfluorene) (F8) layers, effectively confining electrons and holes in the perovskite layer for radiative recombination. We report an infrared radiance of $13.2 \mathrm{~W} \mathrm{sr}^{-1} \mathrm{~m}^{-2}$ at a current density of $363 \mathrm{~mA} \mathrm{~cm} \mathrm{~cm}^{-2}$, with highest external and internal quantum efficiencies of $0.76 \%$ and $3.4 \%$ respectively. In our green lightemitting device with an ITO/PEDOT:PSS $/ \mathrm{CH}_{3} \mathrm{NH}_{3} \mathrm{PbBr}_{3} / \mathrm{F} 8 / \mathrm{Ca} / \mathrm{Ag}$ structure, we achieved a luminance of $364 \mathrm{~cd} \mathrm{~m}^{-2}$ at a current density of $123 \mathrm{~mA} \mathrm{~cm}^{-2}$, giving external and internal quantum efficiencies of $0.1 \%$ and $0.4 \%$ respectively. We show, using photoluminescence studies, that radiative bimolecular recombination is dominant at higher excitation densities. Hence, the quantum efficiencies of the perovskite light-emitting diodes (PeLED) increase at higher current density. This demonstration of effective perovskite electroluminescence offers scope for developing this unique class of materials into efficient and color tunable light emitters for low-cost display, lighting and optical communication applications.

Recent reports on earth-abundant organometal halide based perovskite for high efficiency photovoltaics have demonstrated this class of materials to be excellent semiconductors for optoelectronic devices. ${ }^{1-7}$ Their primary advantages lie in the fact that they can be easily solution processed, require no high temperature heating, and they possess an optical bandgap which is tunable in the visible to infrared regions, ${ }^{8,9}$ making them very attractive materials for use in low-cost and large area optoelectronic applications. Previous works have shown these perovskites to possess strong photoluminescent properties, ${ }^{10,11}$ hence making them potential candidates for use in lightemitting devices. There were previous attempts to fabricate light-emitting devices using related 
perovskite materials. ${ }^{12-14}$ However, electroluminescence could only be achieved at liquid nitrogen temperatures, rendering those devices impractical for applications. In this work, we demonstrate the first high brightness infrared and visible electroluminescence from solution-processed organometal halide perovskites, using two unique device architectures. All electroluminescence and device characteristics were measured in air at room temperature.

In our infrared PeLED, we use a simple 3-layered structure of $\mathrm{TiO}_{2} / \mathrm{CH}_{3} \mathrm{NH}_{3} \mathrm{Pbl}_{3-x} \mathrm{Cl} / \mathrm{F} 8$ (Fig. 1a), which is sandwiched between indium tin oxide (ITO) and $\mathrm{MoO}_{3} / \mathrm{Ag}$ as the cathode and anode respectively. We designed the perovskite to be placed between two large bandgap semiconductors, in a double heterostructure architecture, so as to confine injected charges for better light emission. A thin $\left(25 \mathrm{~nm}\right.$ ) layer of $\mathrm{TiO}_{2}$ was deposited using atomic layer deposition (ALD) onto an ITO-coated glass substrate. The $\mathrm{TiO}_{2}$ serves as an efficient electron injector, as well as a hole-blocking layer for the perovskite device. A thin $(15 \mathrm{~nm})$ layer of perovskite was deposited on the $\mathrm{TiO}_{2}$ by spin-coating, followed by annealing at $100{ }^{\circ} \mathrm{C}$ (see Fig. $1 \mathrm{~b}$ for perovskite structure). The perovskite layer was designed to be thin in order to spatially confine electrons and holes for bimolecular recombination. Given the small exciton binding energy in this material, ${ }^{5,15,16}$ the confinement of injected charges within a thin "well" enhances electron-hole capture and improves radiative recombination. The perovskite film was capped with a $50 \mathrm{~nm}$ layer of F8 polymer by spin-coating from solution. The F8 polymer layer, with a deep ionization potential and a shallow electron affinity, was chosen to form a type-I heterojunction with the perovskite (see Fig. 1c for energy-level diagram). This allows holes to be confined within the perovskite well and electrons to be blocked from exiting via the anode. A high work function $\mathrm{MoO}_{3} / \mathrm{Ag}$ anode was used to provide ohmic hole injection into the device. ${ }^{17}$ The ionization potentials of the materials are estimated from values in the literature, ${ }^{18,19}$ and the electron affinity values are estimated based on the optical bandgap of the materials.

a

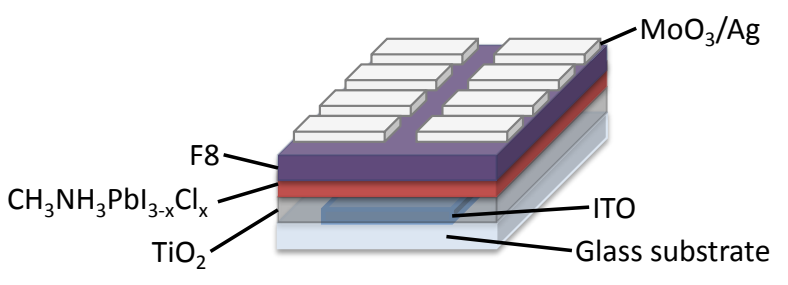

b
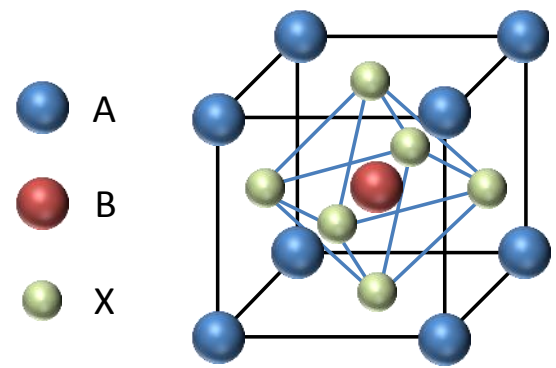

C

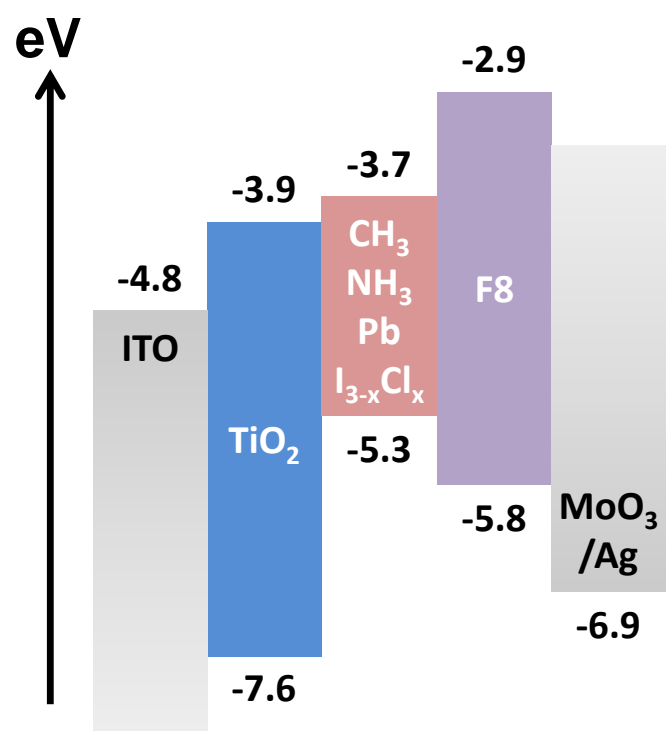

Figure 1 | Structure and energy-level diagram of perovskite LED. a, Device architecture of $\mathrm{CH}_{3} \mathrm{NH}_{3} \mathrm{Pbl}_{3-x} \mathrm{Cl}_{x}$ perovskite light-emitting diode (PeLED). b, Single unit-cell of an $A B X_{3}$ perovskite crystal, where $A$ is methylammonium, $\mathrm{B}$ is $\mathrm{Pb}$ and $\mathrm{X}$ is $\mathrm{I}, \mathrm{Br}$ or $\mathrm{Cl}$. c, Energy-level diagram of different layers of materials in the infrared PeLED, showing conduction and valence band levels with respect to vacuum. 
The optical absorption and emission spectra of the $\mathrm{CH}_{3} \mathrm{NH}_{3} \mathrm{Pbl}_{3-x} \mathrm{Cl}_{x}$ perovskite thin film are shown in Fig. 2. Absorption onset occurs at approximately $780 \mathrm{~nm}$, consistent with previous reports. ${ }^{1}$ The non-zero baseline in the absorption spectra can be attributed to light scattering and interference effects, since we measure a clear absorption edge in photothermal deflection spectroscopy (PDS), which is a technique immune to optical scattering artifacts (Supplementary Fig. 1). A strong near-infrared photoluminescence (PL), centered at $773 \mathrm{~nm}$, was measured when the perovskite thin film was excited with a $532 \mathrm{~nm}$ continuous wave laser. Using the integrating sphere method, ${ }^{20}$ we measured a relatively high photoluminescence quantum efficiency (PLQE) of $26 \%$. The electroluminescence (EL) of the infrared PeLED is slightly blue shifted from the PL, peaking at $754 \mathrm{~nm}$. The emission band is narrow with a full width at half maximum (FWHM) of $35 \mathrm{~nm}$. No electroluminescence was observed from the F8 polymer, indicating that F8 serves only as a holetransporting and electron-blocking layer, and does not participate in light emission.

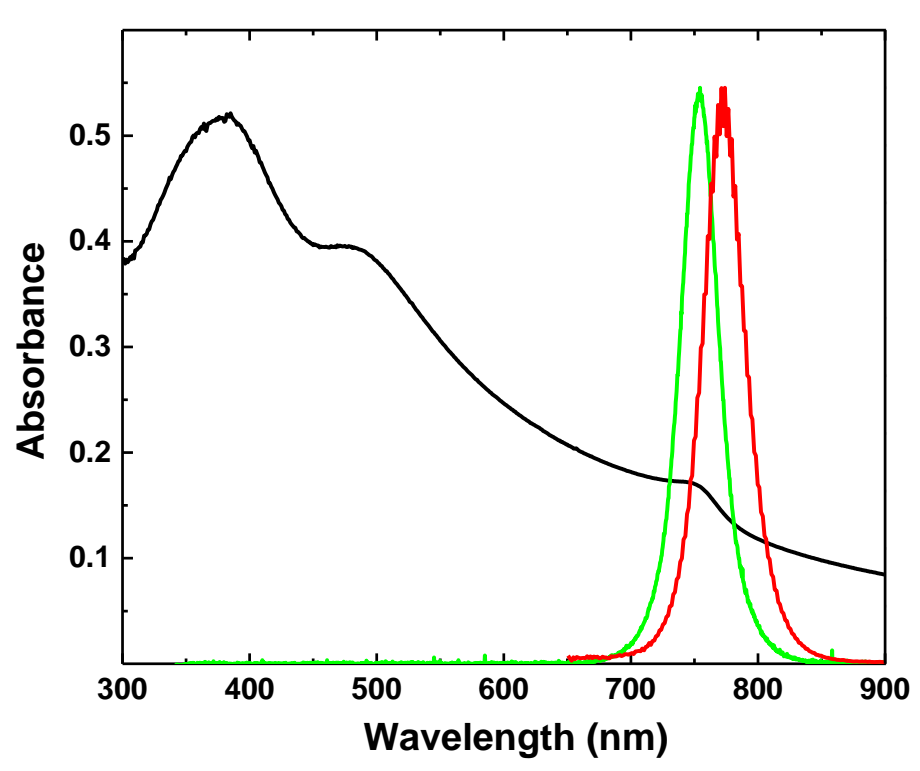

Figure 2 | Absorption and emission spectra of $\mathrm{CH}_{3} \mathrm{NH}_{3} \mathrm{Pbl}_{3-\mathrm{x}} \mathrm{Cl}_{x}$ perovskite. Absorption spectrum (black) onset occurs at $780 \mathrm{~nm}$. Electroluminescence (green) occurs at $754 \mathrm{~nm}$ and photoluminescence (red) occurs at 773 $\mathrm{nm}$.

The current density vs. voltage characteristics and the corresponding radiance of the infrared PeLED is shown in Fig. 3a. A clear turn-on of light emission was observed at $1.5 \mathrm{~V}$, close to the photon emission energy. A radiance of $6.8 \mathrm{~W} \mathrm{sr}^{-1} \mathrm{~m}^{-2}$ was achieved at a current density of 605 $\mathrm{mA} \mathrm{cm}{ }^{-2}$ when driven at $6.2 \mathrm{~V}$. An external quantum efficiency (EQE) of $0.23 \%$ was achieved at $494 \mathrm{~mA} \mathrm{~cm}^{-2}$ and $5.3 \mathrm{~V}$ (Fig. 3b), calculated assuming a Lambertian emission profile. This gives an internal quantum efficiency (IQE) of $1.0 \%$, calculated using the relation IQE $=2 \mathrm{n}^{2}$ EQE. ${ }^{21}$ We selected the refractive index of glass $(n=1.5)$ to estimate IQE because we consider light to be emitted isotropically into the glass substrate, given the thinness $(<<$ wavelength $\lambda$ ) of our emissive perovskite layer. The EQE in our devices rises with increasing voltage and current density, indicating that a high density of charges is required for efficient radiative recombination. 
To investigate the reasons for the decline in radiance and efficiency at higher current densities, we turned to pulse voltage measurements where a bias of $14 \mathrm{~V}$ was applied to drive currents up to $1500 \mathrm{~mA} \mathrm{~cm}^{-2}$. Using square voltage pulses at a width of $1 \mathrm{~ms}$ and frequency of $100 \mathrm{~Hz}$, we achieved a two-times higher radiance of $13.1 \mathrm{~W} \mathrm{sr}^{-1} \mathrm{~m}^{-2}$ at a current density of $1467 \mathrm{~mA} \mathrm{~cm}^{-2}$ (Fig. 3c). This indicates that the device degradation and efficiency drop-off are driven by heating at high current densities since a higher radiance could be achieved when the device is given time to cool between the pulses.

Interestingly, we observed during our pulse experiments that the radiance and quantum efficiency of the PeLED increase across the duration of the voltage pulse, while the current density remains approximately constant (Supplementary Fig. 2). We show, in Supplementary Fig. 3, that this increase in light-emitting efficiency is related to the history of electric field polarization across the device. In our experiments, a device which is pre-polarized with an external bias emits at a higher radiance and efficiency. Over the duration of the voltage pulse, the perovskite device becomes increasingly polarized, hence giving higher electroluminescence with longer pulse durations. This polarization effect is also reflected in the hysteretic current-voltage characteristics of the PeLED, as shown in Supplementary Fig. 4. A potential sweep from forward bias to reverse bias (i.e. larger polarization history to smaller polarization) leads to higher radiance and EQE, compared to a sweep from reverse to forward bias. We postulate that a high polarization voltage drives the ionic traps out of the bulk emissive layer, therefore suppressing non-radiative trap-mediated recombination and enhancing the radiative bimolecular recombination. A detailed discussion can be found in the supplementary information.

In our experiments, we observe an increase in EL quantum efficiency with both increasing voltage and current density (Fig. $3 \mathrm{~b}$ and $3 \mathrm{~d}$ ). In order to investigate the relation of radiative recombination with charge (or excitation) density, we measured photoluminescence quantum efficiency (PLQE) as a function of laser excitation flux (Fig. 3d). We used a thin film structure of $\mathrm{TiO}_{2} / \mathrm{CH}_{3} \mathrm{NH}_{3} \mathrm{Pbl}_{3-\mathrm{x}} \mathrm{Cl}_{x} / \mathrm{F} 8$ that is identical to our devices for measurement. The PLQE rises with laser photon flux in a trend that is similar to the rise of device quantum efficiency with current density, confirming that high charge densities are essential for efficient radiative recombination. In Fig. 3d, we compare IQE vs. current density in the same plot as PLQE vs. absorbed photon flux, and find good agreement between the quantum efficiencies obtained via laser excitation and electrical injection. The extrapolation of IQE suggests that higher electroluminescence quantum efficiency may be achievable at higher current densities. We note that the quantum efficiency of the pulsed device also exhibits the same increase with current density, although efficiencies are lower compared to the steady-state measurements due to the short pulse width of 1 ms (Supplementary Fig. 2). The lower device EL quantum efficiencies compared to the PLQE suggest non-radiative losses by electrical injection, which may be reduced by the optimization of device fabrication process if these losses are predominantly due to high leakage currents.

We have previously demonstrated that radiative recombination in $\mathrm{CH}_{3} \mathrm{NH}_{3} \mathrm{Pbl}_{3-x} \mathrm{Cl}_{x}$ perovskites is bimolecular in nature. ${ }^{10}$ The need for high excitation densities for efficient radiative recombination suggests the presence of a competing non-radiative recombination pathway. Since bimolecular recombination kinetics follow an $n^{2}$ relationship (where $n=$ excitation density), a radiative bimolecular pathway can dominate at higher charge densities. With the fluxes produced in 
our devices, charge densities are relatively low and the competing non-radiative channels dominate, giving rise to a modest EL quantum efficiency.

It is interesting to note that a PLQE of $10 \%$ can be achieved in a $\mathrm{TiO}_{2} / \mathrm{CH}_{3} \mathrm{NH}_{3} \mathrm{Pbl}_{3-\mathrm{x}} \mathrm{Cl} / \mathrm{F} 8$ film structure. This is compared to a PLQE of $26 \%$ for a pristine perovskite film of equivalent thickness at an equivalent laser excitation flux. This confirms the formation of a charge confining well structure in our devices, where excitations are only slightly quenched at the heterojunctions, despite an emissive layer thickness of only $15 \mathrm{~nm}$. To further demonstrate the effectiveness of our thin well structure, we fabricated devices using thicker perovskite films (Supplementary Fig. 5). The radiance and quantum efficiency of the devices decrease markedly at larger perovskite thicknesses, demonstrating the need for spatial confinement of charges to ensure a high rate of electron-hole capture and radiative recombination. In addition, reabsorption losses are likely to be lower in the thinner films.

a

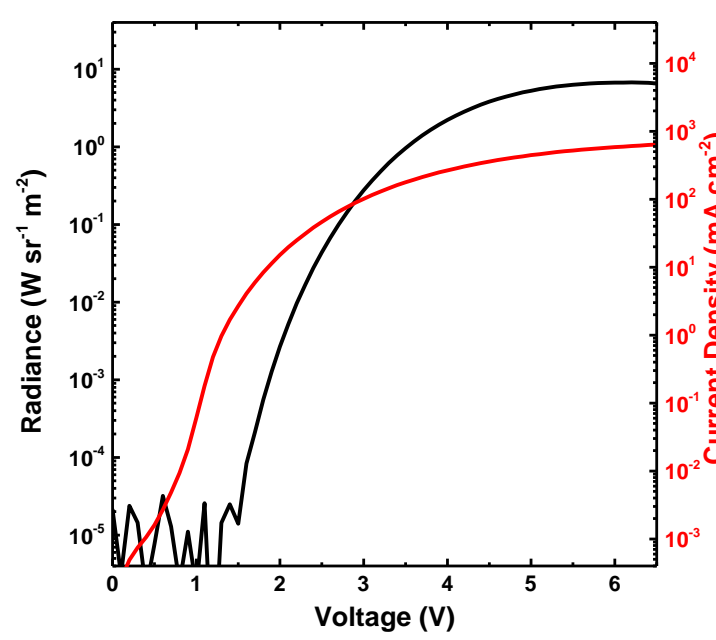

C

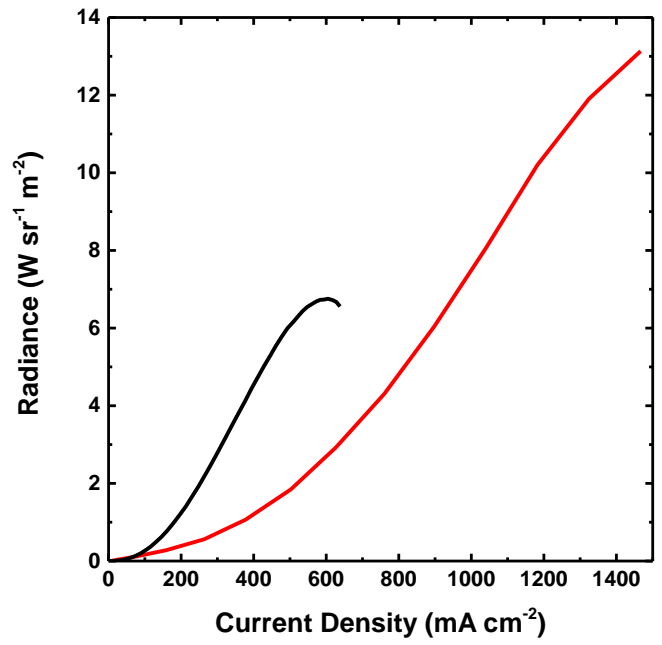

b

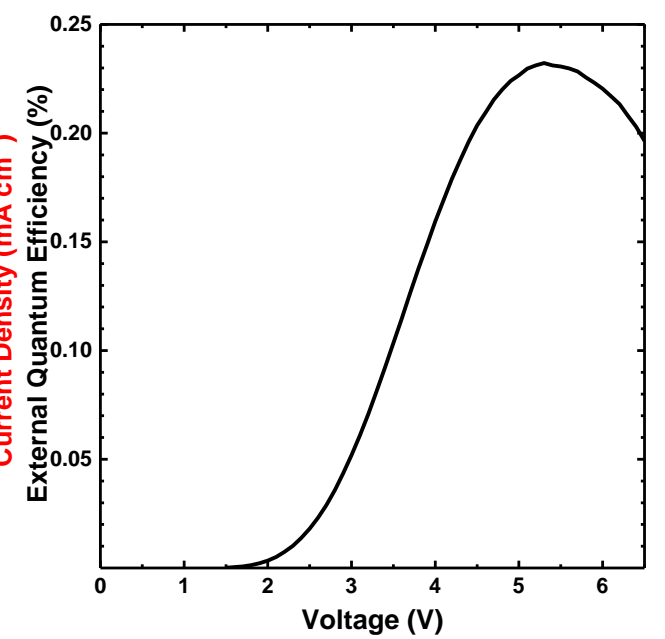

d

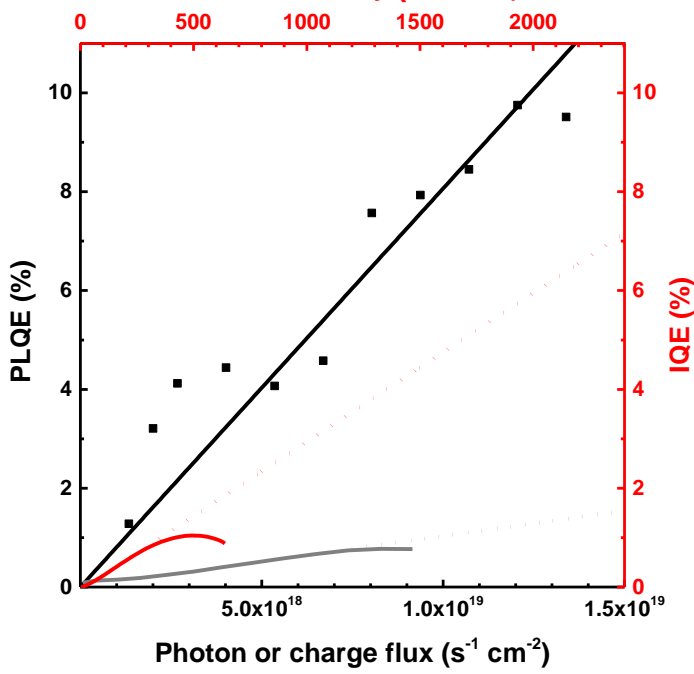

Figure 3 | Device characteristics of infrared PeLED. a, Combined radiance (black) and current density (red) vs. voltage characteristics of the infrared PeLED. The device turns on at $1.5 \mathrm{~V}$. b, External quantum efficiency vs. voltage characteristics of PeLED. c, Radiance vs. current density of PeLED under steady state (black) and pulse 
measurement (red) conditions. For pulse measurement, $1 \mathrm{~ms}$ square voltage pulses were applied at a frequency of $100 \mathrm{~Hz}$. d, Photoluminescence quantum efficiency (PLQE) (black) of $\mathrm{TiO}_{2} / \mathrm{CH}_{3} \mathrm{NH}_{3} \mathrm{Pbl}_{3-\mathrm{x}} \mathrm{Cl}_{\mathrm{x}} / \mathrm{F} 8$ layers as a function of absorbed ( 15\%) photon flux. Device Internal quantum efficiency (IQE) in steady-state measurement (red) and in pulse measurement (grey) are plotted against current density on the same graph for comparison. Dotted lines represent extrapolation of quantum efficiencies towards higher current density.

Our findings suggest that higher charge densities, higher polarization and thinner emission layers are possible routes towards enhancing the electroluminescence efficiency. However, we note that the surface coverage of the $\mathrm{CH}_{3} \mathrm{NH}_{3} \mathrm{Pbl}_{3-x} \mathrm{Cl}_{x}$ perovskite is incomplete ( $\sim 30 \%$ voids) in such thin layers (Supplementary Fig. 6), causing possible contact between the $\mathrm{TiO}_{2}$ and $\mathrm{F} 8$ layers. In order to investigate the effects of electrical shunts at $\mathrm{TiO}_{2} / \mathrm{F} 8$ interfaces, we fabricated a $\mathrm{TiO}_{2} / \mathrm{F} 8$ device without the thin perovskite layer. We find the current density of the $\mathrm{TiO}_{2} / \mathrm{F} 8$ device to be several times higher than the perovskite device at forward bias (Supplementary Fig. 7), indicating that there are possible current losses at the $\mathrm{TiO}_{2} / \mathrm{F} 8$ interface that do not contribute to electroluminescence. Optimization of thin film formation and morphology towards complete perovskite coverage is therefore expected to enhance device radiance and quantum efficiency. We further note that the EL photon flux from the F8-only device is 3 orders of magnitude lower than the perovskite device, confirming that the F8 layer does not participate in light emission but serves only as a holetransporting and electron-blocking layer.

In an effort to optimize our device efficiencies and to minimize luminescence quenching at the $\mathrm{TiO}_{2} /$ perovskite interface, we inserted an ultra-thin $(1 \mathrm{~nm})$ layer of $\mathrm{Al}_{2} \mathrm{O}_{3}$ in between the $\mathrm{TiO}_{2}$ and the perovskite layers using atomic layer deposition. With this minor modification, we achieved a two-fold enhanced radiance of $13.2 \mathrm{~W} \mathrm{sr}^{-1} \mathrm{~m}^{-2}$ at a lower current density of $363 \mathrm{~mA} \mathrm{~cm}^{-2}$ (Fig. 4a). Consequently, the device EQE and IQE increased by more than 3 times to $0.76 \%$ and $3.4 \%$ respectively (Fig. 4b). This level of performance is comparable or better than some of the best colloidal quantum dot infrared light-emitting devices. ${ }^{22,23}$ This enhancement in luminescent efficiency is likely due to the surface-induced nano-structuring of the perovskite $\operatorname{layer}^{24}$ and the suppression of luminescence quenching at the $\mathrm{TiO}_{2} /$ perovskite interface. 
a

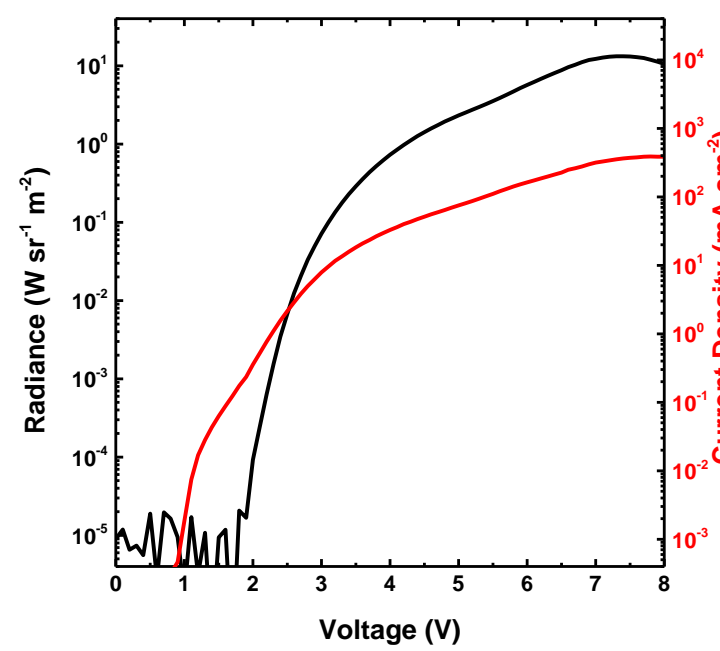

b

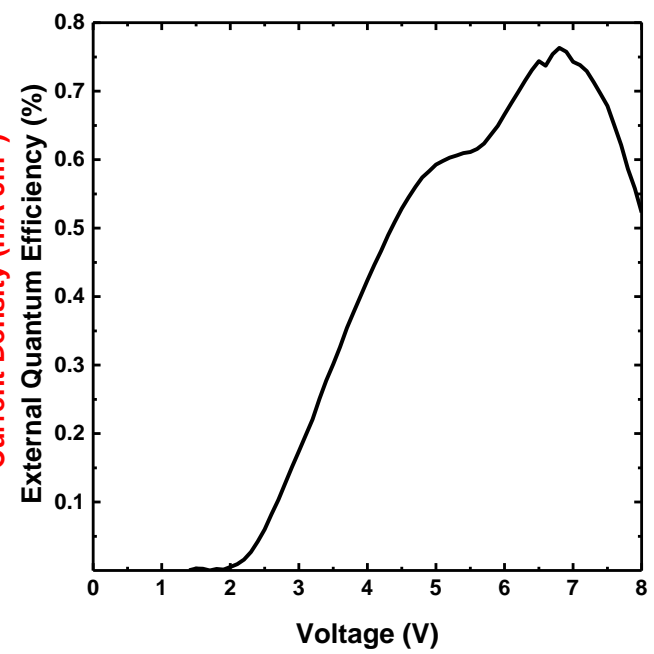

Figure 4 | Device characteristics of infrared PeLED modified with $\mathrm{Al}_{2} \mathrm{O}_{3}$. a, Combined radiance (black) and current density (red) vs. voltage characteristics of a modified $1 \mathrm{TO} / \mathrm{TiO}_{2} / \mathrm{Al}_{2} \mathrm{O}_{3}(1 \mathrm{~nm}) / \mathrm{CH}_{3} \mathrm{NH}_{3} \mathrm{Pbl}_{3}$ ${ }_{x} \mathrm{Cl} / \mathrm{F} 8 / \mathrm{MoO}_{3} / \mathrm{Ag}$ infrared PeLED. b, External quantum efficiency vs. voltage characteristics of modified infrared PeLED.

In order to demonstrate the application of organometal halide perovskite as visible light emitters, we utilized the larger bandgap $\mathrm{CH}_{3} \mathrm{NH}_{3} \mathrm{PbBr}_{3}$ as a green emitter in our PeLED devices. Since a larger bandgap makes it more challenging to achieve electron injection from $\mathrm{TiO}_{2}$ into the perovskite conduction band, we turned to an inverted device structure with an ITO/PEDOT:PSS/CH $\mathrm{CH}_{3} \mathrm{NH}_{3} \mathrm{PbBr}_{3} / \mathrm{F} 8 / \mathrm{Ca} / \mathrm{Ag}$ architecture. PEDOT:PSS and calcium were utilized as ohmic hole and electron injectors respectively. The F8 polymer $(50 \mathrm{~nm})$ serves as a spacer layer for electron transport and to prevent emission quenching near the Ca metal interface. In order to spatially confine injected charges for efficient radiative recombination, we fabricated $\mathrm{CH}_{3} \mathrm{NH}_{3} \mathrm{PbBr}_{3}$ to a thickness of $20 \mathrm{~nm}$ (film morphology shown in Supplementary Fig. 8). As shown in Fig. 5a, bright green electroluminescence was achieved at $517 \mathrm{~nm}$. The $\mathrm{PL}$ of $\mathrm{CH}_{3} \mathrm{NH}_{3} \mathrm{PbBr}_{3}$ perovskite is slightly red-shifted from the EL, peaking at $524 \mathrm{~nm}$ with a PLQE of $7 \%$ when excited with a $405 \mathrm{~nm}$ laser. The device turns on at $3.3 \mathrm{~V}$ and reaches a luminance of $364 \mathrm{~cd} \mathrm{~m}^{-2}$ at a current density of $123 \mathrm{~mA}$ $\mathrm{cm}^{-2}$, as shown in Fig. 5b. This gives an efficiency of $0.3 \mathrm{~cd} \mathrm{~A}^{-1}$, or an EQE of $0.1 \%$ and an IQE of $0.4 \%$ (Fig. 5c), assuming a Lambertian emission profile. Similar to the infrared device, the EL quantum efficiency increases with injection current density (Fig. 5d), demonstrating a need for high charge densities to achieve efficient radiative recombination. We also demonstrate red electroluminescence at $630 \mathrm{~nm}$ using a $\mathrm{CH}_{3} \mathrm{NH}_{3} \mathrm{PbBr}_{2} \mathrm{I}$ mixed halide perovskite in the same device architecture (device characteristics in Supplementary Fig. 9), showing the versatility and wide bandgap tunability of these organometal halide perovskites. 
a

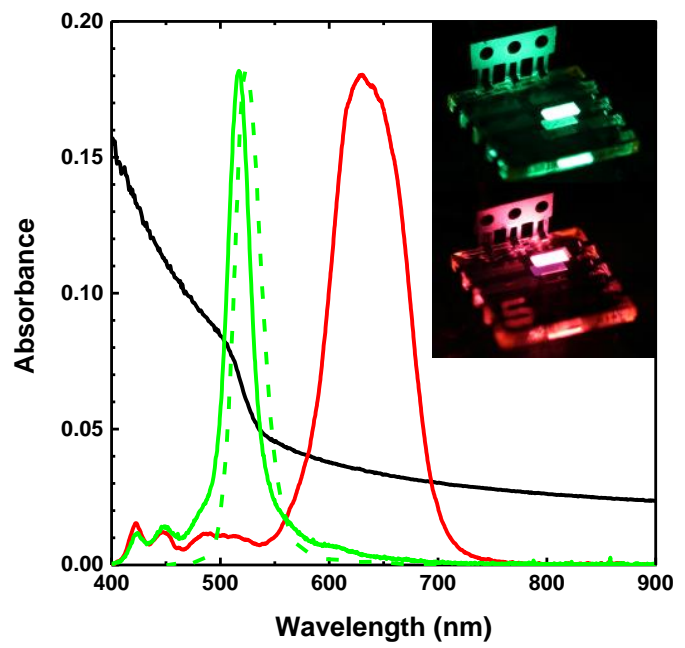

C

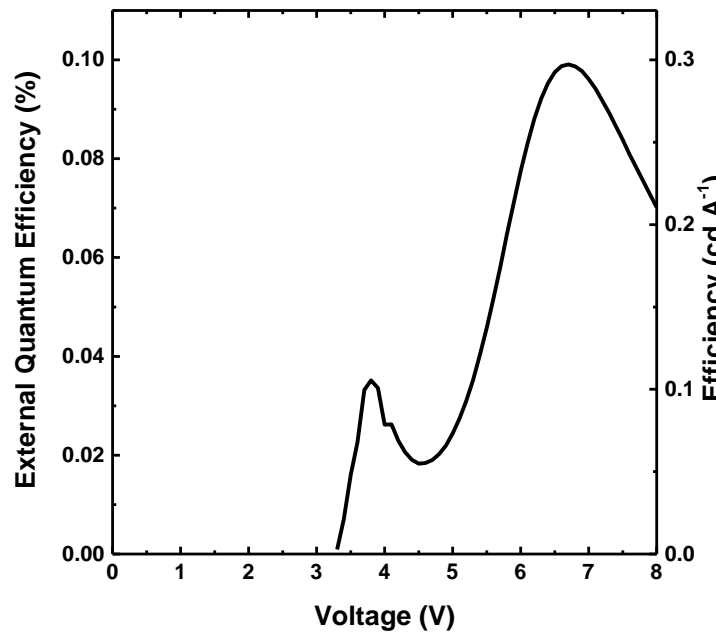

b

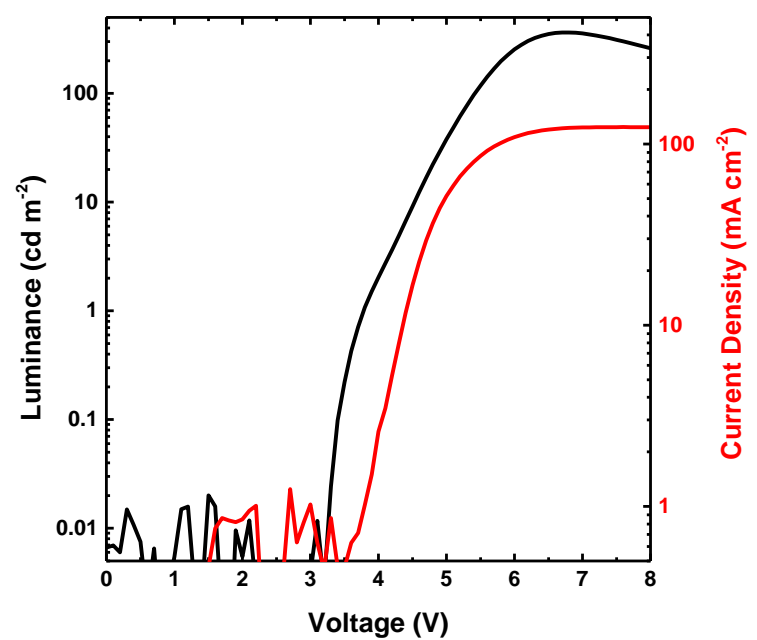

d

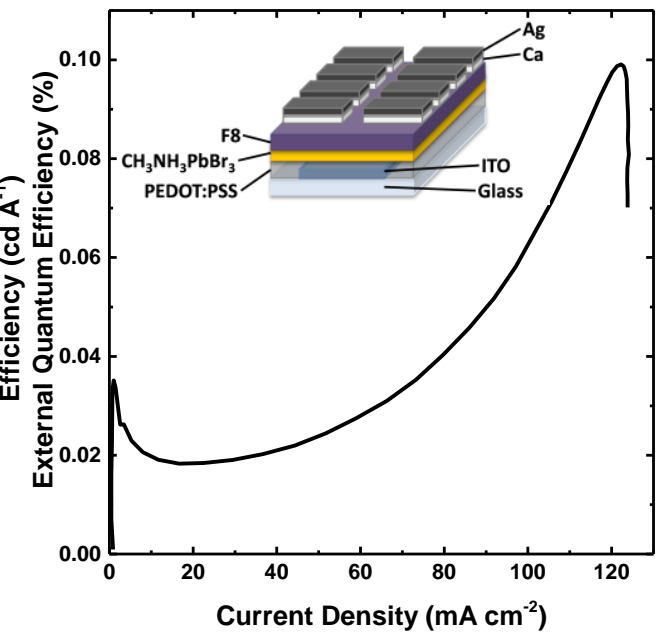

Figure 5 | Device characteristics of visible PeLED. a, Absorption (black), electroluminescence (green, solid) and photoluminescence (green, dashed) spectra of $\mathrm{CH}_{3} \mathrm{NH}_{3} \mathrm{PbBr}_{3}$ perovskite. Electroluminescence of $\mathrm{CH}_{3} \mathrm{NH}_{3} \mathrm{PbBr}_{2} \mathrm{I}$ mixed halide perovskite shown in red. Inset image shows uniform green and red electroluminescence from ITO/PEDOT:PSS/ $\mathrm{CH}_{3} \mathrm{NH}_{3} \mathrm{PbBr}_{3} / \mathrm{F} 8 / \mathrm{Ca} / \mathrm{Ag}$ and ITO/PEDOT:PSS/ $\mathrm{CH}_{3} \mathrm{NH}_{3} \mathrm{PbBr}_{2} \mathrm{l} / \mathrm{F} 8 / \mathrm{Ca} / \mathrm{Ag} \mathrm{PeLED}$ respectively. b, Combined luminance (black) and current density (red) vs. voltage characteristics of green PeLED. The device turns on at 3.3 V. c, External quantum efficiency vs. voltage characteristics of green PeLED. d, External quantum efficiency vs. current density of green PeLED. Inset diagram shows green PeLED device structure.

Our demonstration of bright visible and infrared electroluminescence from organometal halide based perovskites shows great promise in the development of this class of materials for large area optoelectronics or electrically-pumped lasing applications. ${ }^{10,25}$ Furthermore, our work exemplifies the fact that an efficient solar cell material is generally also a good light emitter, as given by the Shockley-Queisser detailed balance limit calculations. ${ }^{26,27}$ It is interesting that bright electroluminescence could be achieved using a simple thin emitter realized by solution processing. Given the versatility and low-cost processability of these organometal halide perovskites, they may quickly find their way into the display and lighting industry. 


\section{Materials and Methods}

F8 polymer was provided by Cambridge Display Technology (CDT) and was used as received. All other chemicals were purchased from Sigma-Aldrich and were used as received.

$\mathrm{CH}_{3} \mathrm{NH}_{3} \mathrm{Pbl}_{3-x} \mathrm{Cl}$. Perovskite Synthesis. Methylammonium iodide $\left(\mathrm{CH}_{3} \mathrm{NH}_{3} \mathrm{l}\right)$ was prepared by adding 33 wt \% methylamine solution in ethanol $(24 \mathrm{~mL})$ and $57 \mathrm{wt} \%$ hydroiodic acid in water $(10 \mathrm{~mL})$ to 100 $\mathrm{mL}$ of absolute ethanol. The reaction mixture was stirred at room temperature in a nitrogen atmosphere. The solvent was removed by rotary evaporation until white crystals started to appear. The product was collected using Büchner funnel filtration and was dried overnight under vacuum at $80^{\circ} \mathrm{C}$. The mixed halide perovskite precursor solution was prepared by mixing $\mathrm{CH}_{3} \mathrm{NH}_{3}$ land $\mathrm{PbCl}_{2}$ in a 3:1 molar ratio in anhydrous $\mathrm{N}, \mathrm{N}$-dimethylformamide to give a concentration of $5 \mathrm{wt} \%$.

$\mathrm{CH}_{3} \mathrm{NH}_{3} \mathrm{PbBr}_{3}$ Perovskite Synthesis. Methylammonium bromide $\left(\mathrm{CH}_{3} \mathrm{NH}_{3} \mathrm{Br}\right)$ was prepared by adding $33 \mathrm{wt} \%$ methylamine solution in ethanol $(24 \mathrm{~mL})$ and $48 \mathrm{wt} \%$ hydrobromic acid in water $(8.5 \mathrm{~mL})$ to $100 \mathrm{~mL}$ of absolute ethanol. The reaction mixture was stirred at room temperature. The solvent was removed by rotary evaporation. The obtained white crystals were washed with anhydrous diethyl ether and recrystallized in ethanol. The perovskite precursor solution was prepared by mixing $\mathrm{CH}_{3} \mathrm{NH}_{3} \mathrm{Br}$ and $\mathrm{PbBr}_{2}$ in a 3:1 molar ratio in anhydrous $\mathrm{N}, \mathrm{N}$-dimethylformamide to give a concentration of $5 \mathrm{wt} \%$. For the $\mathrm{CH}_{3} \mathrm{NH}_{3} \mathrm{PbBr}_{2} \mathrm{I}$ mixed-halide precursor solution, we mixed the individual $\mathrm{CH}_{3} \mathrm{NH}_{3} \mathrm{PbBr}_{3}$ and $\mathrm{CH}_{3} \mathrm{NH}_{3} \mathrm{Pbl}_{3}$ precursor solutions in a molar ratio of 2:1 to give an overall concentration of $5 \mathrm{wt} \%$.

Infrared PeLED Fabrication. ITO-coated glass substrates were cleaned successively with acetone and isopropanol. $\mathrm{TiO}_{2}(25 \mathrm{~nm})$ was grown onto the cleaned substrates at $225{ }^{\circ} \mathrm{C}$ with atomic layer deposition (ALD), using titanium tetrachloride $\left(\mathrm{TiCl}_{4}\right)$ and water as precursors. The substrates were transferred into a nitrogen filled glovebox for further fabrication. The $\mathrm{CH}_{3} \mathrm{NH}_{3} \mathrm{Pbl}_{3-x} \mathrm{Cl}_{x}$ perovskite precursor solution was spin-coated onto the $\mathrm{TiO}_{2}$ at $3000 \mathrm{rpm}$ for 60 seconds, and annealed at $100{ }^{\circ} \mathrm{C}$ for 5 minutes to give a thin perovskite film with an average thickness of $\sim 15 \mathrm{~nm}$, as determined by atomic force microscopy (AFM). A solution of F8 in chlorobenzene $(10 \mathrm{mg} / \mathrm{mL}$ ) was spin-coated onto the perovskite layer at $3000 \mathrm{rpm}$ for 60 seconds to give a $50 \mathrm{~nm}$ film. $\mathrm{MoO}_{3}(5 \mathrm{~nm})$ and $\mathrm{Ag}(100 \mathrm{~nm})$ were successively deposited by vacuum thermal evaporation. Devices were tested in air without encapsulation.

Green PeLED Fabrication. ITO-coated glass substrates were cleaned successively with acetone and isopropanol, followed by 10 minutes oxygen plasma treatment. PEDOT:PSS (Clevios P VP Al 4083) was spin-coated onto the substrate at $6000 \mathrm{rpm}$ for 30 seconds, and annealed at $140{ }^{\circ} \mathrm{C}$ for 30 minutes in a nitrogen atmosphere. The $\mathrm{CH}_{3} \mathrm{NH}_{3} \mathrm{PbBr}_{3}$ perovskite precursor solution was spin-coated onto PEDOT:PSS at $3000 \mathrm{rpm}$ for 30 seconds and annealed at $100{ }^{\circ} \mathrm{C}$ for 15 minutes to give a perovskite film thickness of $\sim 20 \mathrm{~nm}$. A solution of F8 in chlorobenzene $(10 \mathrm{mg} / \mathrm{mL})$ was spin-coated onto the perovskite layer at $3000 \mathrm{rpm}$ for 30 seconds to give a $50 \mathrm{~nm}$ film. Ca $(20 \mathrm{~nm})$ and Ag (100 $\mathrm{nm}$ ) were successively deposited by vacuum thermal evaporation. Devices were tested in air without encapsulation.

PeLED Characterization. Current vs. voltage characteristics were measured using a Keithley 2400 Source Measure Unit (SMU). Photon flux was measured simultaneously using a calibrated silicon photodiode centered over the light-emitting pixel. Radiance in $\mathrm{W} \mathrm{sr}^{-1} \mathrm{~m}^{-2}$ and luminance in $\mathrm{cd} \mathrm{m}^{-2}$ 
were calculated based on the emission function of the PeLED, and on the known spectral response of the silicon photodiode. External quantum efficiency was calculated, assuming a Lambertian emission profile. Electroluminescence spectra were measured using a Labsphere CDS-610 spectrometer.

PLQE Measurement. The PLQE of the thin film samples was measured using an integrating sphere method, as reported in the literature. ${ }^{20}$ A continuous wave $532 \mathrm{~nm}$ green diode laser with an excitation power of $10-100 \mathrm{~mW}$ and a focused beam spot of $\sim 0.3 \mathrm{~mm}^{2}$ was used to photo-excite the samples. Emission was measured using an Andor iDus DU490A InGaAs detector. During measurements, the samples were kept at room temperature under a constant stream of nitrogen. Samples were prepared in the structure $\mathrm{TiO}_{2} / \mathrm{CH}_{3} \mathrm{NH}_{3} \mathrm{Pbl}_{3-x} \mathrm{Cl} / \mathrm{F} 8$ on top of a spectrosil fused silica substrate, similar to the PeLED device structure.

Pulse LED Measurement. A square voltage pulse with a pulse width of $1 \mathrm{~ms}$ and frequency of $100 \mathrm{~Hz}$ was applied to the device using a HP8116A Pulse/Function generator. A dual-channel Agilent Technologies DSO6032A oscilloscope, set to $50 \Omega$ impedance, was connected in series to the device and the function generator to determine the current through the device. The electroluminescence was monitored using a calibrated Si photodiode, connected to the $2^{\text {nd }}$ channel of the oscilloscope (1 $\mathrm{M} \Omega$ ) via a Thorlabs PDA200C photodiode amplifier. 


\section{References}

1 Lee, M. M., Teuscher, J., Miyasaka, T., Murakami, T. N. \& Snaith, H. J. Efficient Hybrid Solar Cells Based on Meso-Superstructured Organometal Halide Perovskites. Science 338, 643-647 (2012).

2 Kim, H.-S. et al. Lead lodide Perovskite Sensitized All-Solid-State Submicron Thin Film Mesoscopic Solar Cell with Efficiency Exceeding 9\%. Sci. Rep. 2 (2012).

3 Burschka, J. et al. Sequential deposition as a route to high-performance perovskitesensitized solar cells. Nature 499, 316-319 (2013).

4 Liu, M., Johnston, M. B. \& Snaith, H. J. Efficient planar heterojunction perovskite solar cells by vapour deposition. Nature 501, 395-398 (2013).

5 Stranks, S. D. et al. Electron-Hole Diffusion Lengths Exceeding 1 Micrometer in an Organometal Trihalide Perovskite Absorber. Science 342, 341-344 (2013).

6 Xing, G. et al. Long-Range Balanced Electron- and Hole-Transport Lengths in OrganicInorganic CH3NH3PbI3. Science 342, 344-347 (2013).

$7 \mathrm{Heo}, \mathrm{J}$. H. et al. Efficient inorganic-organic hybrid heterojunction solar cells containing perovskite compound and polymeric hole conductors. Nat Photon 7, 486-491 (2013).

8 Stoumpos, C. C., Malliakas, C. D. \& Kanatzidis, M. G. Semiconducting Tin and Lead lodide Perovskites with Organic Cations: Phase Transitions, High Mobilities, and Near-Infrared Photoluminescent Properties. Inorganic Chemistry 52, 9019-9038 (2013).

9 Noh, J. H., Im, S. H., Heo, J. H., Mandal, T. N. \& Seok, S. I. Chemical Management for Colorful, Efficient, and Stable Inorganic-Organic Hybrid Nanostructured Solar Cells. Nano Letters 13, 1764-1769 (2013).

10 Deschler, F. et al. High Photoluminescence Efficiency and Optically Pumped Lasing in Solution-Processed Mixed Halide Perovskite Semiconductors. The Journal of Physical Chemistry Letters 5, 1421-1426 (2014).

11 Schmidt, L. C. et al. Nontemplate Synthesis of $\mathrm{CH} 3 \mathrm{NH} 3 \mathrm{PbBr} 3$ Perovskite Nanoparticles. Journal of the American Chemical Society 136, 850-853 (2014).

12 Era, M., Morimoto, S., Tsutsui, T. \& Saito, S. Organic-inorganic heterostructure electroluminescent device using a layered perovskite semiconductor ( $6 \mathrm{H} 5 \mathrm{C} 2 \mathrm{H} 4 \mathrm{NH} 3) 2 \mathrm{PbI} 4$. Applied Physics Letters 65, 676-678 (1994).

13 Hattori, T., Taira, T., Era, M., Tsutsui, T. \& Saito, S. Highly efficient electroluminescence from a heterostructure device combined with emissive layered-perovskite and an electrontransporting organic compound. Chemical Physics Letters 254, 103-108 (1996).

14 Chondroudis, K. \& Mitzi, D. B. Electroluminescence from an Organic-Inorganic Perovskite Incorporating a Quaterthiophene Dye within Lead Halide Perovskite Layers. Chemistry of Materials 11, 3028-3030 (1999).

15 Tanaka, K. et al. Comparative study on the excitons in lead-halide-based perovskite-type crystals CH3NH3PbBr3 CH3NH3PbI3. Solid State Communications 127, 619-623 (2003).

16 Hirasawa, M., Ishihara, T., Goto, T., Uchida, K. \& Miura, N. Magnetoabsorption of the lowest exciton in perovskite-type compound (CH3NH3)Pbl3. Physica B: Condensed Matter 201, 427430 (1994).

17 Lu, L.-P., Kabra, D., Johnson, K. \& Friend, R. H. Charge-Carrier Balance and Color Purity in Polyfluorene Polymer Blends for Blue Light-Emitting Diodes. Advanced Functional Materials 22, 144-150 (2012).

18 Abrusci, A. et al. High-Performance Perovskite-Polymer Hybrid Solar Cells via Electronic Coupling with Fullerene Monolayers. Nano Letters 13, 3124-3128 (2013).

19 Hwang, J. et al. Photoelectron Spectroscopic Study of the Electronic Band Structure of Polyfluorene and Fluorene-Arylamine Copolymers at Interfaces. The Journal of Physical Chemistry C 111, 1378-1384 (2006). 
20 de Mello, J. C., Wittmann, H. F. \& Friend, R. H. An improved experimental determination of external photoluminescence quantum efficiency. Advanced Materials 9, 230-232 (1997).

21 Greenham, N. C., Friend, R. H. \& Bradley, D. D. C. Angular Dependence of the Emission from a Conjugated Polymer Light-Emitting Diode: Implications for efficiency calculations. Advanced Materials 6, 491-494 (1994).

22 Tessler, N., Medvedev, V., Kazes, M., Kan, S. \& Banin, U. Efficient Near-Infrared Polymer Nanocrystal Light-Emitting Diodes. Science 295, 1506-1508 (2002).

23 Sun, L. et al. Bright infrared quantum-dot light-emitting diodes through inter-dot spacing control. Nat Nano 7, 369-373 (2012).

24 Choi, J. J., Yang, X., Norman, Z. M., Billinge, S. J. L. \& Owen, J. S. Structure of Methylammonium Lead lodide Within Mesoporous Titanium Dioxide: Active Material in High-Performance Perovskite Solar Cells. Nano Letters 14, 127-133 (2013).

25 Xing, G. et al. Low-temperature solution-processed wavelength-tunable perovskites for lasing. Nat Mater 13, 476-480 (2014).

26 Shockley, W. \& Queisser, H. J. Detailed Balance Limit of Efficiency of p-n Junction Solar Cells. Journal of Applied Physics 32, 510-519 (1961).

27 Miller, O. D., Yablonovitch, E. \& Kurtz, S. R. Strong Internal and External Luminescence as Solar Cells Approach the Shockley-Queisser Limit. Photovoltaics, IEEE Journal of 2, 303-311 (2012).

\section{Acknowledgements}

We thank EPSRC (UK) for financial support. Z.K.T. thanks the Singapore National Research Foundation (Energy Innovation Program Office) for the research scholarship. T.B. thanks the LMU Center of NanoScience, the Excellence Cluster Nanosystems Initiative Munich (NIM) and the Bavarian Network "Solar Technologies Go Hybrid" for financial support.

\section{Author contributions}

Original device architectures conceived by Z.K.T. Z.K.T. designed and fabricated the PeLED, performed most experiments and data analyses, and wrote the paper. R.S.M. optimized the electron-injection layers in devices. M.L.L. fabricated the red PeLED. P.D., R.H. and F.H. prepared the perovskite materials. R.H., F.D. and M.P. assisted with PLQE studies. A.S. performed PDS studies. L.M.P. and D.C. assisted with experiments. T.B. and H.J.S. provided important insights. R.H.F. guided the work.

\section{Additional information}

Supplementary information this accompanies at www.nature.com/naturenanotechnology. Reprints and permission information is available online at http://npg.nature.com/reprintsandpermissions/. Correspondence and requests for materials should be addressed to R.H.F. 